\title{
OGS improvements in the year 2011 in running the Northeastern Italy Seismic Network
}

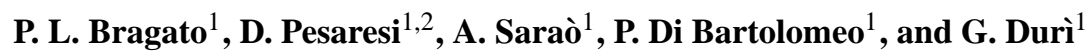 \\ ${ }^{1}$ OGS (Istituto Nazionale di Oceanografia e di Geofisica Sperimentale), Udine, Italy \\ ${ }^{2}$ Istituto Nazionale di Geofisica e Vulcanologia, Roma, Italy \\ Correspondence to: D. Pesaresi (dpesaresi@inogs.it)
}

Received: 27 March 2013 - Revised: N.A. - Accepted: 4 April 2013 - Published: 30 April 2013

\begin{abstract}
The Centro di Ricerche Sismologiche (CRS, Seismological Research Center) of the Istituto Nazionale di Oceanografia e di Geofisica Sperimentale - OGS (Italian National Institute for Oceanography and Experimental Geophysics) in Udine (Italy) after the strong earthquake of magnitude $\mathrm{Mw}=6.4$ occurred in 1976 in the Italian FriuliVenezia Giulia region, started to operate the Northeastern Italy Seismic Network: it currently consists of 12 very sensitive broad band and 21 simpler short period seismic stations, all telemetered to and acquired in real time at the OGS-CRS data centre in Udine. Real time data exchange agreements in place with other Italian, Slovenian, Austrian and Swiss seismological institutes lead to a total number of 93 seismic stations acquired in real time, which makes the OGS the reference institute for seismic monitoring of Northeastern Italy, as shown in Fig. 1 (Bragato et al., 2011; Saraò et al., 2010). Since 2002 OGS-CRS is using the Antelope software suite as the main tool for collecting, analyzing, archiving and exchanging seismic data, initially in the framework of the EU Interreg IIIA project "Trans-national seismological networks in the South-Eastern Alps" (Bragato et al., 2010; Pesaresi et al., 2008). SeisComP is also used as a real time data exchange server tool. In order to improve the seismological monitoring of the Northeastern Italy area, at OGS-CRS we tuned existing programs and created ad hoc ones like: a customized web server named PickServer to manually relocate earthquakes, a script for automatic moment tensor determination, scripts for web publishing of earthquake parametric data, waveforms, state of health parameters and shaking maps, noise characterization by means of automatic spectra analysis, and last but not least scripts for email/SMS/fax alerting. A new OGSCRS real time seismological website (http://rts.crs.inogs.it/) has also been operative since several years.
\end{abstract}

\section{Data management}

The Antelope software suite is used at OGS-CRS as the main data acquisition tool for the Northeastern Italy Seismic Network run by OGS. The main OGS-CRS Antelope server is running in Udine on a two nodes SUN Fire V240 cluster: the main module does data acquisition, automatic locations, data archiving and exchange, plus the alert system via Short Message Service (SMS), email, and fax. Another two workstations - an old Linux and a new Mac PRO - running Antelope at the OGS-CRS headquarters in Udine are used for post-processing including ShakeMaps and manual relocations. Data is also forwarded for redundancy to a SUN Fire V245 Antelope machine at Protezione Civile della Regione Friuli-Venezia Giulia headquarters in Palmanova. Data is shared on the main Antelope cluster in Udine also with a SeisComP server for data exchange.

During the year 2011, the installation of the last release of the Antelope software suite 5.1-64 on the Apple MacPRO proved to be very fast, reliable and efficient. At the moment the test configuration of Antelope at OGS-CRS is made of main seismic data acquisition on the SUN cluster and automatic location on the MacPRO, as shown in Fig. 2. Other automated customized, self-written scripts take care of state of health display and drum plot waveform display on the web, for remote monitoring of the functioning of the Northeast Italy Seismic Network.

\section{Real time analysis}

Real Time Analysis at OGS-CRS is based on the core Antelope running on the SUN cluster, robust and reliable: all automatic earthquake location and magnitude determination is made on this cluster of workstations. Earthquake parametric 


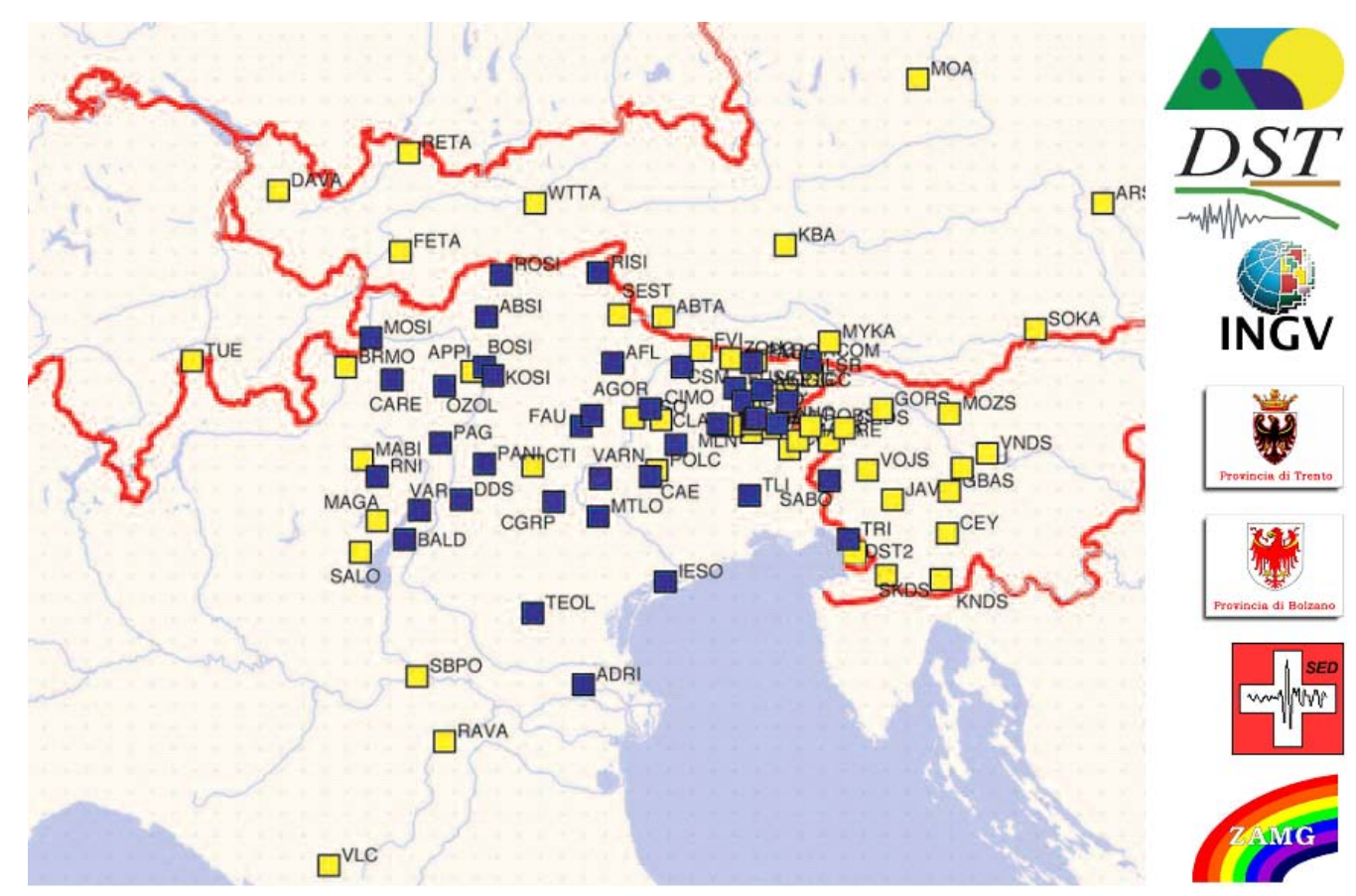

Fig. 1. The OGS Virtual Seismic Network: 33 OGS stations (blue squares) and 60 stations contributed by other institutions (yellow squares) in real time.

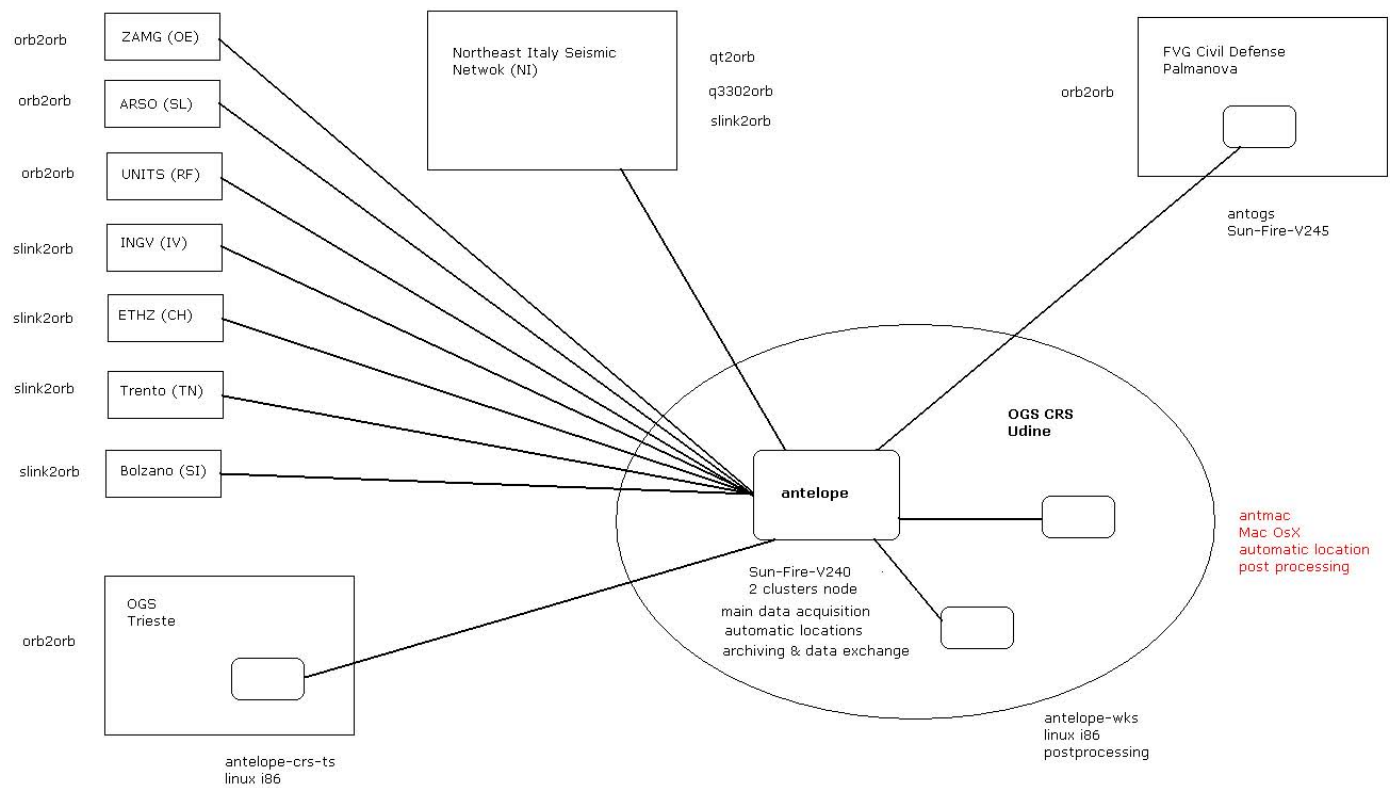

Fig. 2. Schematic of Antelope configuration at OGS.

data (location and magnitude but also expected macroseismic effects) are automatically notified via Short Message System (SMS), fax, email and web to governmental institutions like the Civil Defences of the Veneto and of the Friuli-Venezia Giulia regions. The OGS-CRS Real Time Seismological website (RTS, http://rts.crs.inogs.it/) has also been operative since several years: the RTS website shows classic earth- quake locations parametric data plus shaking maps and moment tensor information computed using the Dreger (2003) algorithm; lately also daily PSD quality check of seismic stations plots have been added. Manual revision of automatic earthquake locations are performed in a completely revised web site custom made at OGS-CRS named "PickServer", based on JAVA technology: it uses the SeisGram2K 


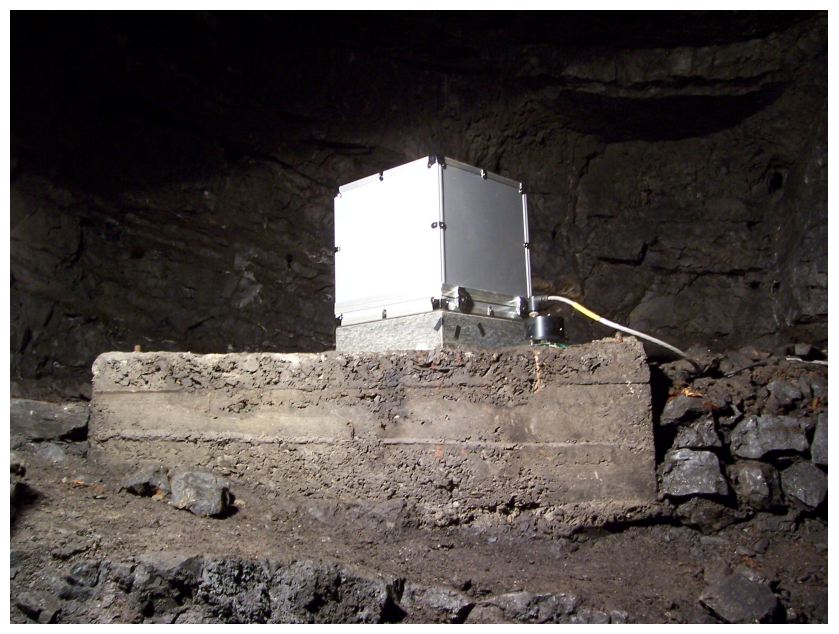

Fig. 3. Cludinico Station (CLUD): thermal insulation of the seismometer with aluminium box.

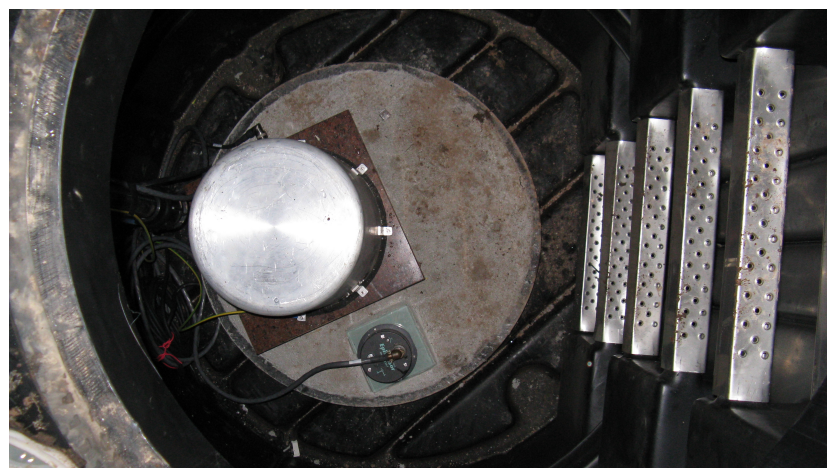

Fig. 4. Seismometers installed on a pier at the bottom of a plastic container, with extra thermal insulation (ZOU station).

software (Antony Lomax Scientific software, last access: 19 April 2012) for quick visualization and signal processing of picks and waveforms read from the Antelope system.

\section{Seismic stations}

At OGS-CRS we spent a considerable amount of efforts in improving the long-period performances of broadband seismic stations, either by carrying out full re-installations and/or applying thermal insulations to the seismometers. It is very well know in fact that broad band (BB) and even more very broad band (VBB) seismometers are very sensitive to temperature and pressure variations at long periods.

We used several methods to counteract the influences on $\mathrm{BB}$ and VBB seismometers of temperature and pressure at long periods. The most natural one is to try to install (V)BB seismic stations in underground natural caves or artificial tunnels. The deeper the cave/tunnel, the more stable will be the temperature and minimum will be the pressure variation. The second methods consists in thermally insulating (V)BB

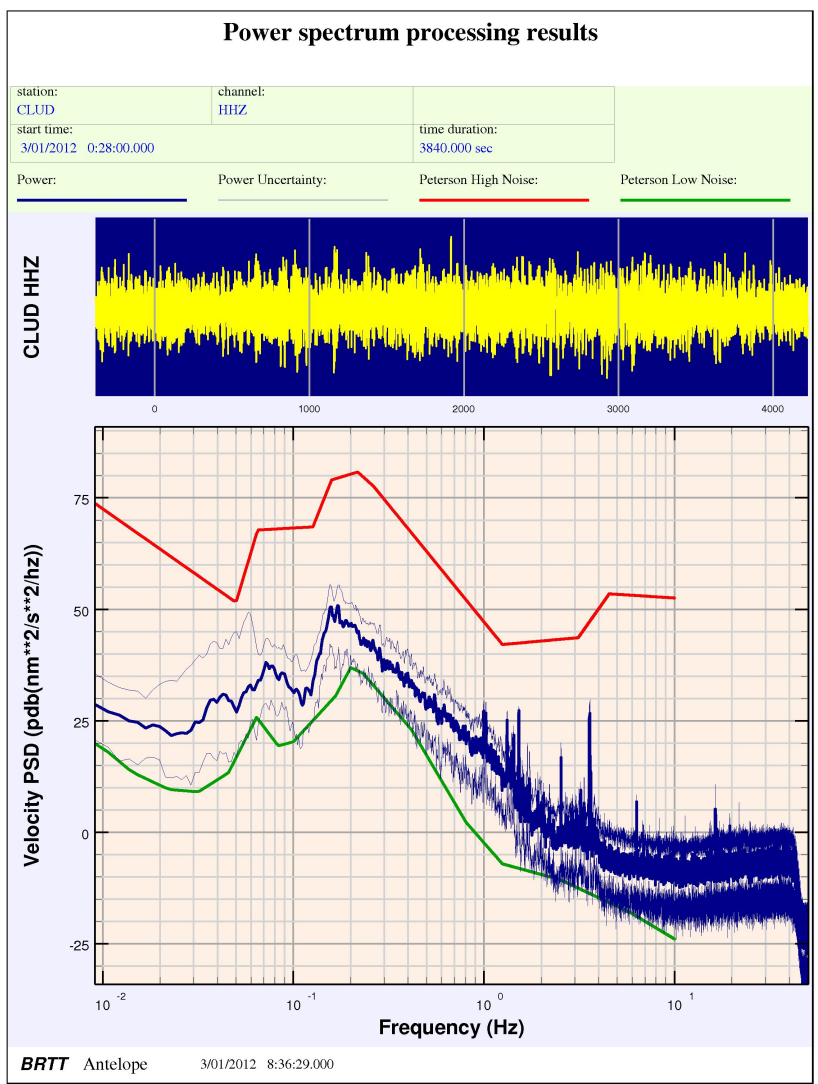

Fig. 5. PSD of seismic noise at CLUD station.

seismometers: at OGS-CRS we developed an aluminium box that serves the purpose, as illustrated in Fig. 3; the thermal insulator must be close enough to the seismometer itself not to allow convection currents in the air heated around the seismometer by the seismometer itself, which lead to long period noise, but not to touch the seismometer. The third and last method used at OGS-CRS in improving the performances of the Northeast Italy Seismic Network is the usage of a plastic container to be buried underground several meters deep to host the seismic station as shown in Fig. 4. Such a kind of plastic containers are usually easily available for general construction purpouses, and they are cheap and easy to install, especially compared to the cost of excavating a tunnel for the only scope of installing a seismic station. These efforts lead to good long period performances of $(\mathrm{V}) \mathrm{BB}$ seismic station of the Northeast Italy Seismic Station as illustrated in Fig. 5, where the blu lines indicating average power spectral density (PSD) seismic noise computed in an $1 \mathrm{~h}$ time window with standard deviation at the Cludinico (CLUD) station are very close to the green line of the Low Noise curves estimated by Peterson (1993).

Efforts have been put also in strengthening the reliability of data links, exploring the use of redundant satellite/radio/GPRS links, as shown in Fig. 6. 


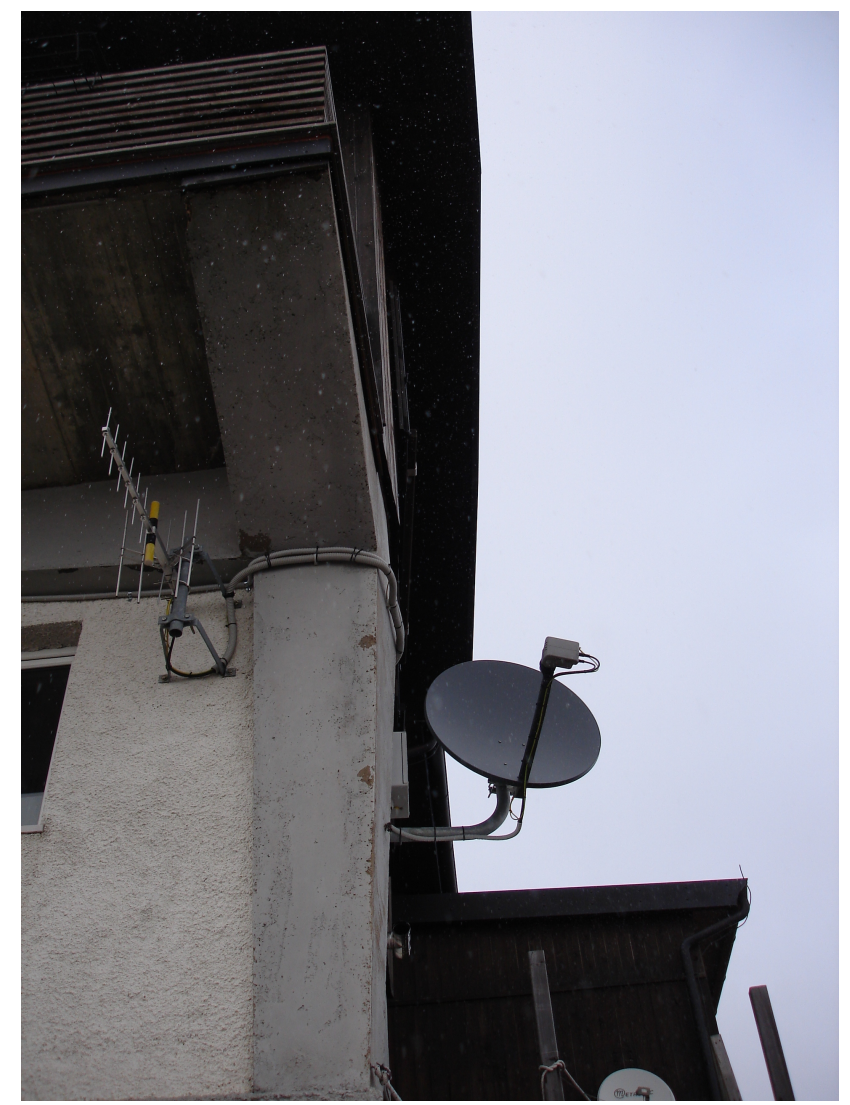

Fig. 6. Redundant data links: left UHF radio, right ASTRA connect satellite (BALD station).

Acknowledgements. The technical staff of the OGS Centro di Ricerche Sismologiche (CRS) is acknowledged for its continuous effort in maintaining the seismic network. The Civil Defense of the Regione Autonoma Friuli-Venezia Giulia together with the Regione del Veneto and Provincia di Trento financially support the seismometric network maintained by the OGS Centro di Ricerche Sismologiche (CRS).

\section{References}

Antony Lomax Scientific software: http://alomax.free.fr/alss, last access: 19 April, 2012.

Bragato, P. L., Costa, G., Horn, N., Pahor, J., Pesaresi, D., Lenhardt, W., and Zivcic, M.: The usage of Antelope for acquiring end exchanging data in South-Eastern Alps: present configuration and future perspectives, poster presented at European Seismological Commission 32nd General Assembly, Montpellier, France, 6-10 September 2010, 2010.

Bragato, P. L., Di Bartolomeo, P., Pesaresi, D., Plasencia Linares, M. P., and Saraò, A.: Acquiring, archiving, analyzing and exchanging seismic data in real time at the Seismological Research Center of the OGS in Italy, Ann. Geophys., 54, 67-75, doi:10.4401/ag-4958, 2011.

Dreger, D. S.: Time-Domain Moment Tensor INVerse Codel (TDMT-INVC) Release 1.1, in: International Handbook of Earthquake and Engineering Seismology, Vol. B, 1627, 2003.

Peterson, J.: Observations and modelling of background seismic noise, US Geological Survey Open-file report 93-322, Albuquerque, New Mexico, 1993.

Pesaresi, D., Bragato, P. L., Di Bartolomeo, P., Saraò, A., and Bernardi, P.: Monitoring in real time the North East Italy seismicity: the OGS-CRS experience with the Antelope software suite, XXXI European Seismological Commission (ESC) General Assembly 2008, Crete, Greece, 7-12 September 2008, 2008.

Saraò, A., Pesaresi, D., Bragato, P. L., Di Bartolomeo, P., and Plasencia Linares, M. P.: Acquiring, archiving, analyzing and exchanging seismic data in real time at the Seismological Research Center of the OGS in Italy: an updated view, poster presented at European Seismological Commission 32nd General Assembly, Montpellier, France, 6-10 September 2010, 2010. 